\title{
EL POEMA DE MIO CID (un comentario)
}

\author{
ManUel Ariza Viguera \\ (Universidad de Sevilla) \\ RESUMEN
}

My research is a philological commentary of a fragment of the Cantar de Mio Cid. I study the text problems, and the external structure - rhyme, formulistic dictions, dialogue, etc. - After, I study the internal structure - temps, tense, adjective, semantic structures, syntax, etc. Finally I examine any interesting words.

\section{INTRODUCCIÓN}

Afortunadamente existen ya varios comentarios del Poema del Mio Cid, pues muchas ediciones suelen traer alguno ${ }^{1}$; de ellos destacaremos los de Ian Michael ${ }^{2}$ y Rafael Cano ${ }^{3}$. Nuestro comentario va a tener dos partes. En la primera estudiaremos los problemas que se plantean en las ediciones de un texto medieval con un único manuscrito, aunque sea tardío; en la segunda haremos un estudio lingüístico del poema.

No entraremos en temas como quién era el famoso Per Abad, aunque sí tendremos que tocar el de la datación del Poema. Sea éste de mediados del siglo XII -como es lo más cierto- o de principios del siglo XIII, conviene recordar que el manuscrito conservado es de principios del siglo XIV. Este hecho nos va a plantear problemas que no son exclusivos del poema de Mio Cid, sino de una gran cantidad de obras medievales; me refiero al de la fijación del texto primitivo, o, dicho de otra forma, al problema de saber hasta donde se pueda qué es lo que cambió el copista y por qué. Hay veces que tenemos manuscritos de diferentes épocas, lo que nos permite estudiar estos cambios, pero no siempre es así, por lo que suele ser lugar común echar las culpas a los copistas de las anomalías que encontramos en un texto. En nuestro caso, al contar sólo con un manuscrito, no es posible establecer la comparación citada, y sólo por medio de las «incorrecciones» del texto podremos saber algo de lo que cambió Per Abad, o quien fuera el autor de la copia conservada.

1 Citaré a modo de ejemplo los que realizan J.J. Bustos (Madrid, Alianza Ed., 1983), y Emilia Sánchez. Carrasco (Barcelona, Plaza \& Janes, 1984).

2 «Tres duelos en el Poema de Mio Cid», en VV.AA. El comentario de textos 4 La poesía medieval, Madrid, Castalia, 1984, pp. 85-104. Desde otra perspectiva hay que citar también a J. Talens: «Teoría y técnica del análisis poético», en VV.AA. Elementos para una semiótica del texto artístico, Madrid, Cătedra, 1978, pp. 83-95.

3 En su libro Análisis filológico de textos, Madrid, Taurus, 1991, pp. 50-61. 


\section{EDICIONES}

En primer lugar vamos a copiar el texto del manuscrito ${ }^{4}$ y la transcripción de Menéndez Pidal en su edición crítica ${ }^{5}$, a continuación compararemos la edición «vulgata» de don Ramón ${ }^{6}$ con las ofrecidas por Ian $\mathrm{Michael}^{7}$ y Colin Smith ${ }^{8}$.

\section{I manuscrito}

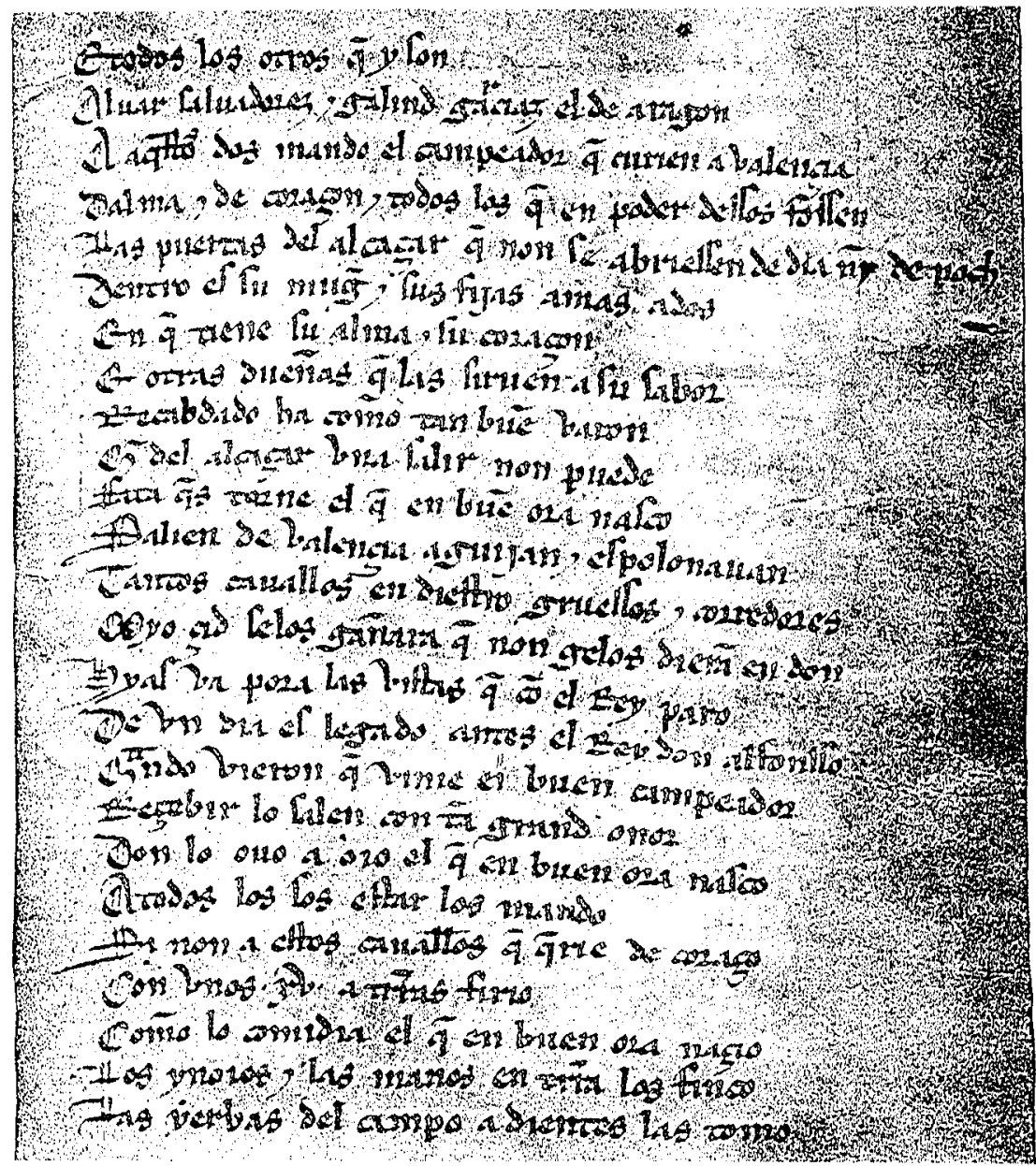

Tomado de la edición facsímil de Burgos, 1982

Madrid, Espasa Calpe, 1964 (4*).

Madrid, Espasa Calpe, 1963.

Madrid, Castalia, 1976.

8 Madrid, Cátedra, 1976. 


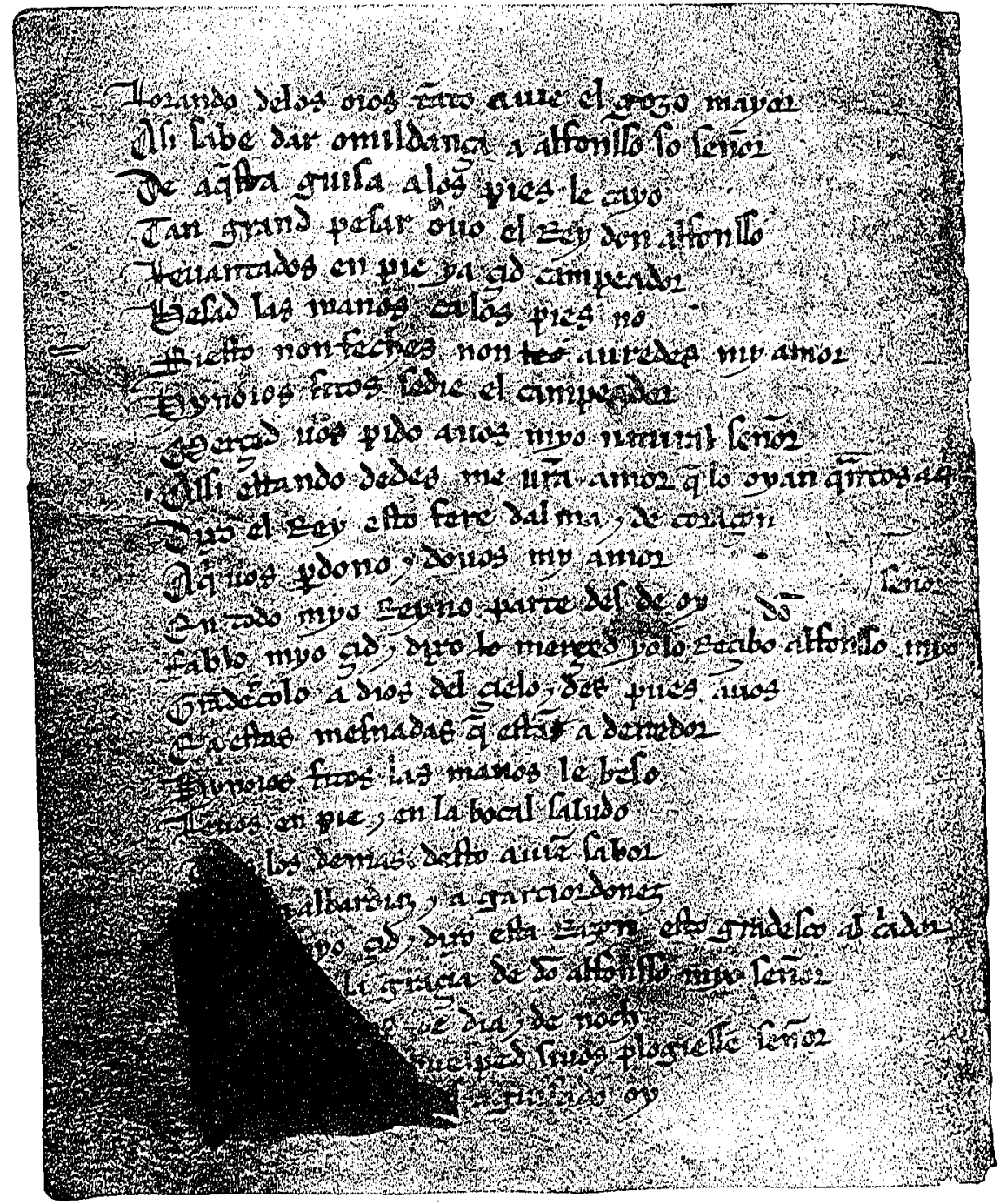


II Texto de Menéndez Pidal

2002 Las puertas del alcaçar que non Se abrieSSen de dia nin de noch,

Dentro eS su mugier \& Sus fijas amas a dos

En que tiene $\mathrm{Su}$ alma \& Su coraçón,

2005 E otras dueñas que las Siruen aSu Sabor;

Recabdado ha, commo tan buen varon,

Que del alcaçar vna Salir non puede

Fata ques torne el que en bue $n$ ora naSco.

Salien de Valençia, aguijan \& eSpolonauan.

2010 Tantos cauallos en dieStro, grueSSos \& corredores,

Myo Çid Selos gañara, que non gelos dieran en don

HyaS va pora las viStas que con el rey paro.

De vn dia eS legado ante el rey don Alfonsso.

Quando vieron que vinie el buen Campeador,

2015 Reçebir lo Salen con tan grand onor.

Don lo ouo a oio el que en buen ora naSco,

Atodos los Sos eStar los mandó,

Si non a eStos caualleros que querie de coraçon;

Con vnos XV a tierras firio,

2020 Commo lo comidia el que en buen ora naçio,

Los ynoios \& las manos en tierra los finco,

Las yerbas del campo a dientes las tomo,

Lorando delos oios, tanto auie el gozo mayor;

ASi Sabe dar omildança a AlfonSso So Señor.

2025 De aqueSta guiSa alos pies le cayo.

Tan grand peSar ouo el rey don AlfonSSo:

«Leuantados en pie, ya çid Campeador,

BeSad las manos, ca los pies no;

SieSto non feches, non auredes my amor.»

2030 Hynoios fitos Sedie el Campeador:

«Merçed uos pido auos, myo natural Señor,

ASSi eStando, dedes me uueStra amor, que lo oyan quantos aqui Son.»

Dixo el rey «eSto fere dalma \& de coraçon;

Aqui uos perdono \& douos my amor,

2035 En todo myo reyno parte deS de oy.»

Fablo myo Çid \& dixo: «merçed yolo reçibo, AlfonSSo myo Señor,

Gradescolo a Dios del çielo \& des pues auos,

E a eStas meSnadas que eStan a derredor.»

Hynoios fitos las manos le beSó,

2040 Leuos en pie \& en la bocal Saludo.

Todos los demas deSto auien Sabor;

PeSo a Albardiaz \& a Garciordoñez. 
Fablo myo Çid \& dixo eSta razon: «eSto gradeSco al Criador, Quando he la graçia de don AlfonSSo myo Señor,

2045 Valer me a Dios de dia \& de noch.

FueSSedes my hueSped, Siuos plogieSSe, Señor.»

Dixo el rey: «non eS aguiSado oy:

Vos agora legaStes, \& nos vinjemos anoch;

Myo hueSped Seredes, Çid Campeador,

2050 E cras feremos lo que plogiere auos.»

BeSo le la mano myo Çid, lo otorgo.

ESSora Sele omillan los yffantes de Carrion:

«Omillamos nos, Çid, en buen ora naSquieStes uos!

En quanto podemos andamos en uueStro pro.»

2055 ReSpuSo mio Çid: «aSSi lo mande el Criador!»

Las puertas del alcáçer, mio Cid lo mandó, que non se abriessen de día nin de noch; dentro es su muguier e sus fijas amas a dos, en que tiene su alma e so coraçon,

2005 e otras dueñas que las sirven a su sabor; recabdado ha, commo tan buen varón, que del alcáçer una salir non puode, fata ques torne, el que en buen ora naçió. Salien de Valençia, aguijan $a$ espolón.

2010 Tantos caballo en diestro, guressos e corredores, mio Çid se los gañara, que non ge los dieran en don.

Hyas vas pora las vista que con el rey paró.

De un día es llegado antes el rey don Alfons. Quando vieron que vinie el buen Campeador,

2015 reçebir lo salen con tan gran onor.

Don lo ovo a ojo el que en buen ora naçió.

a todos los sos estar los mandó, si non a estos cavalleros que querie de coraçón.

Con unos quinze a tierras firió,

2020 como los comidía el que en buen ora naçió;

los inojos e las manos en tierra los fincó, las yerbas del campo a dientes las tomó.

llorando de los ojos, tanto avié el gozo mayor; assí sabe dar omildança a Alfons so señor.

2025 De aquesta guisa a los piedes le cayó; tan grand pesar ovo el rey don Alfons: «Levantados en pies, ya Çid Campeador; 
$\gg$ besad las manos, ca los piedes no;

»si esto non feches, non avredes mi amor.»

2030 Hinojos fitos sedie el Campeador, »iMerced vos pido a vos, mio natural señor, »assí estando, dédesme vuestra amor, $2032^{\mathrm{b}}$ »que lo oyan todos quantos aquí son.» Dixo el rey: «esto feré d'alma e de coraçon; »aquí vos perdono e dovos mi amor.»

2035 »ên todo mio reyno parte desde oy.» Fabló mio Cid e dizo esta razón: $2036^{\mathrm{b}}$ «merced; yo lo reçibo, Alfonso mio señor; "gradéscolo a Dios del çielo e después a vos, »e a estas mesnadas que están a derredor.» Hinojos fitos las manos le besó.

2040 Levós en pie e en la bócal saludó. Todos los demás desto avien sabor; pesó a Álvar Díaz e a Garci Ordóñez. Fabló mio Çid e dixo esta razón: «Esto gradesco al padre Criador, »quando he la garçia de Alfons mio señor;

2045 »valer me a Dios de día e de noch.

"Fossedes mio huesped, si vos ploguiesse, señor.»

Dixo el rey: «non es aguisado oy:

»vos agora llegastes, e nos viniemos anoch;

III Texto de Ian Michael

$2001^{\mathrm{b}}$ e todos los [otros] que en poder d'éssos fossen;

las puertas del alcáçar

$2002^{b}$ que non se abriessen de día ni de noch, dentro de su mugier e sus fijas amas a dos, en que tiene su alma e su coraçon,

2005 e otras dueñas que las sirven a su sabor; rrecabdado ha, commo tan buen varón, que del alcáçar una salir non puede fata ques' torne el que en buen ora nasco. Salien de Valençia, aguijan e espolonavan,

2010 tantos cavallos en diestro, gruessos e corredores, Mio Cid se los gañara, que non ge los dieran en don; yas' va pora las vista que con el rrey paró. De un día es llegado antes el rrey don Alfonso; quando vieron que vinié el buen Campeador 
2015 rreçebirlo salen con tan grad onor.

Dón lo ovo a oio el que en buen ora nasco, a todos los soso estar los mandó sinon a estos cavalleros que querié de coraço[n]; con unos quinze a tierras' firió, 2020 los inoios e las manos en tierra los finçó, las yerbas del campo a dientes las tomó, llorando de los oios tanto avié el gozo mayor; assí sabe dar omildnaça a Alfonso so señor.

2025 De aquesta guisa a los pies le cayó; tan grand pesar ovo el rrey don Alfonso: «Levantados en pies, ya Çid Campeador, »besad las manos ca los pies no[n];

»si esto non feches, non avredes mi amor.»

2030 Inoios fitos sedié el Campeador:

«Merçed vos pido a vós, mio natural señor, »assí estando, dédesme vuestra amor

$2032^{b}$ »que lo oyan quantos aquí son."

Dixo el rrey: «Esto feré d'alma e de coraçon;

»aquí vos perdono e dovos mi amor

$2035 »[e]$ en todo mio rreino partes desde oy."

Fabló Mio Çid e dixo:

$2036^{\mathrm{b}}$ « Merced! Yo lo rreçibo, Alfonso mio señor; "gradéscolo a Dios del çielo e después a vós »e a estas mesnadas que están aderredor.»

\section{Texto de Colin Smith}

Martin Muñoz e Martin Antolinez el burgales de pro, el obispo don Jeronimo cor[o]nado mejor, Alvar Alvarez e Alvar Sa[1]vadorez,

1995 Muño Gustioz el cavallero de pro,

Galind Garçiaz el que fue de Aragon:

estos se adoban por ir con el Campeador

e todos los otros que i son.

Alvar Salvadorez e Galind Garçiaz el de Aragon

2000 a aquestos dos mando el Campeador

$2000^{\mathrm{b}}$ que curien a Valençia d'alma e de coraçon

e todos los que en poder dessos fossen;

las puertas del alcaçar que non se abriessen de dia nin de noch, dentro es su mugier e sus fijas a mas a dos en que tiene su alma e su coraçon, 
2005 e otras dueñas que las sirven a su sabor; recabdado ha - commo tan buen varonque del alcaçar una salir non puede fata ques torne el que en buen ora na[çi]o. Salien de Valençia, aguijan [a] espolon:

2010 tantos cavallos en diestro guressos e corredores mio Çid selos gañara, que no gelos dieran en don. Hyas va pora las vistas que con el rey paro. De un día es legado antes el rey don Alfonsso; quando vieron que vinie el buen Campeador

2015 reçebir lo salen con tan grand onor.

Dont lo ovo a ojo el que en buen ora na[çi]o a todos los sos estar los mando si non a estos cavalleros que querie de coraçon; con unos xv a tierras firio

2020 commo lo comidia el que en buen ora naçio; los inojos e las manos en tierra los finco, las yerbas del campo a dientes las tomo lorando de los ojos, tanto avie el gozo mayor, asi sabe dar omildnaça a Alfonsso so señor.

2025 De aquesta guisa a los pies le cayo. Tan grand pesar ovo el rey don Alfonsso: ¡Levantados en pie ya Çid Campeador! Besad las manos, ca los pies no; si esto non feches non avredes mi amor.

2030 Hinojos fitos sedie el Campeador: ¡Merçed vos pido a vos mio natural señor! Assi estando dedes me vuestra amor, $2032^{\text {b }}$ que lo oyan quantos aqui son. Dixo el rey: 'Esto fere d'alma e de coraçon! Aqui vos perdono e dovos mi amor,

2035 [y] en todo mio reino parte desde oy. Fablo mio Çid e dixo [esta razon]:

$2036^{\mathrm{b}}$ iMerced! Yo lo reçibo, Alfonsso mio señor; ¡gradescolo a Dios del çielo e despues a vos e a estas mesnadas que estan aderredor! Hinojos fitos las manos le beso 2040 levos en pie y en la bocal saludo. Todos los demas desto avien sabor; peso a Albar Diaz e a Garçi Ordoñezç Fablo mio Çid e dixo esta razon: 


\subsection{Comentario}

Para facilitar el cotejo de las diferentes versiones copiaré solamente de aquellos versos en los que difieren los editores citados 9 .

(verso 2002)

MP Las puertas del alcáçer, mio çid lo mandó,

IM Las puertas del alcáçar

CS Las puertas del alcáçar que non se abriessen de día nin de noch

MP y IM (2002 bis) que non se abriessen de día nin de noch;

CS

El verso 2002 del manuscrito es claramente hipermétrico. C. Smith prefiere mantenerlo; Pidal reconstruye lo que pudo ser el original -en cursiva-; I. Michael reconoce la hipermetría, y la necesidad de desdoblar, en consecuencia, el verso original, pero no acepta la solución pidaliana.

(verso 2007)

MP que del alcaçer una salir non puode, (IM y CS alcaçar y puede)

Menéndez Pidal modifica el texto conservado poniendo lo que debió decir el texto originario. la forma alcaçer era la predominante en el siglo XII, y la diptongación en /wo/ de puode es obligada por la rima O-E. Ni I. Michael ni C. Smith admiten las correcciones de D. Ramón.

(verso 2008)

MP fata ques torne el que en buen ora naçio (IM nascó, CS na[çi]ó)

C. Smith admite la modificación de Pidal, no así I. Michael.

(verso 2009)

MP y CS Salien de Valençia aguijan a espolón

IM Salien de Valençia aguijan e espolonavan

Es claro que el texto está deturpado porque no rima en O-E como los demás de la serie. la solución a espolón es muy antigua. De nuevo I. Michael prefiere seguir el texto del manuscrito.

(verso 2036)

MP y CS Fabló mio çid e dixo esta razón

IM Fabló Mio çid e dixo

9 Las siglas empleadas son MP= Menéndez Pidal, IM= Iam Michael, $C S=$ Colin Smith. 
Nos encontramos con otro verso hipermétrico que M. Pidal divide, pero, como el final del hemistiquio - dixo- no rima en O-E, don Ramón añade el sintagma esta razón, fórmula que se repite en el verso 2041. Una vez más C. Smith lo acepta, pero no I. Michael.

(verso 2043)

MP, IM, y CS Fabló mio çid e dixo esta razón

MP Esto grdesco al padre Criador

IM y CS Esto gradesco al Criador

Este otro verso hipermétrico es modificado por Pidal en el segundo hemistiquio añadiendo la palabra padre para darle una mayor longitud al segundo verso, lo que no es aceptado por I. Michael ni por C. Smith.

De lo examinado hasta ahora podemos sacar las siguientes conclusiones: el que más modifica el texto es don Ramón porque pretende acercarse a lo que pudo ser el texto primitivo. las «correcciones» pidalianas son aceptadas a veces por C. Smith — versos 2008 y 2036 -. Por el contrario I. Michael es el que más sigue el texto primitivo - versos 2008 y 2009 - generalmente no acoge los añadidos de Pidal — versos 2036 y 2041 - Sin embargo I. Michael modifica más que C. Smith la grafía del texto. Pondré dos ejemplos: en el verso 2023 aparece lorando, forma que mantiene C. Smith, frente a M. Pidal e I. Michael que ponen llorando; en el verso 2030 el texto pone hinoios, con H antietimológica, forma que adoptan C. Smith y M. Pidal, mientras que I. Michael suprime la $\mathrm{H}$.

Por otra parte los tres modifican las grafías suprimiendo las Y y las U del texto. Según lo examinado, ¿cuál es la mejor edición o la más recomendable? Pues la verdad, las tres son espléndidas ${ }^{10}$. Entonces ¿para qué sirve lo que hemos hecho?, pues para observar qué postura adoptan tres grandes profesores ante los problemas de un texto con un único manuscrito. Sin duda habrá - haydefensores de los tres, porque de lo que se trata no es de criticar, sino de examinar el problema de la conveniencia o no de «reconstruir» un texto.

\section{COMENTARIO}

Lo tradicional sería empezar haciendo un resumen del argumento del fragmento y después analizar las grafías y el sistema fonológico ${ }^{11}$. No vamos a hacerlo, sino que nos vamos a limitar a estudiar el problema de la lengua originaria y las posibles modificaciones introducidas por el copista.

${ }_{10}$ Y no son las únicas. La citada de J.J. Bustos y la de E. Enriquez son también recomendables.

11 Para ello ver el comentario de Rafael Cano, cit. 
Al copista se deben sin duda los versos hepermétricos, las faltas de rima - - puede (v 2007), espolonauan (v 2009) - o la forma alcaçar; como también a él se deben seguramente las grafías con $v$-por ejemplo en el verso $2002 v a$, vistas -, las grafías con $Y$ en primera posición de grupo vocálico - myo (v 2011), las formas con /1/ procedente de PL-latino-lorando (v 2023) $1^{12}$ - y la supresión de la $e$ paragógica (vid la conservación de la primitiva rima O-E en el verso 2010 corredores).

Tema también de amplia discusión en los últimos tiempos es el de los posibles aragonesismos del Poema. Aun cuando ya Pidal señaló algunos, han insistido en su existencia los defensores de la tesis de una cronología tardía (es decir: el poema se compuso a principios del siglo XIII), como son Ubieto, Lacarra, Pattison, Pellen, etc. No es este el momento de discutir sus argumentos ${ }^{13}$, por lo que sólo nos fijaremos en los que aparecen en nuestro texto.

La diptongación en wo --sustituida por we en la copia que tenemos (v 2007)se ha dicho que puede ser rasgo aragonés, por cuanto es sabido que el castellano fija tempranamente la forma de sus diptongos; sin embargo la vacilación en la diptongación no es dialectal, sino, al contrario, signo de la temprana datación del Poema. El diptongo en wo lo encontramos también en el Auto de los Reyes Magos y en la Disputa del alma y el cuerpo; a mediados del siglo XII, en un documento de Osma, hay siete ejemplos de $o$ y uno de we ${ }^{14}$.

También se ha dicho que la conservación de $\mathrm{PL}$ - (plorando) era rasgo aragonés. Efectivamente la citada conservación fonética del grupo latino es rasgo oriental de la Península -- a palatalización no se produce en aragonés o en catalán ${ }^{15}$ - pero no siempre palatalizó en español — cf. plomo, planta, etc ${ }^{16}$ - y además hemos de tener en cuenta que en un principio la palatalización debió tener connotaciones sociolingüísticas, y por ello no aparecen en la Fazienda de Ultramar, o en el Auto de los Reyes Magos o en la Disputa del alma y el cuerpo, aun cuando sabemos que ya se producía en los siglos XI y XII ${ }^{17}$.

${ }^{12}$ Puesto que, al parecer, la patalización del grupo debía tener connotaciones sociolingüísticas en el siglo XII.

${ }^{13}$ Remitoa los trabajos de mi maestro Rafael Lapesa recogidos en su libroEstudios de historialingüística española, Madrid, 1985. Al lector le interesaría consultar el fundamental libro de F. López Estada: Panorama crítico sobre el Poema del Cid, Madrid, 1982. Un buen resumen de la cuestión en el prólogo de la edición de F. Marcos Marín, Madrid, Alhambra, 1985.

${ }_{14}$ Vid. R. Lapesa, ob. cit, pp. 19-21.

${ }^{15}$ Salvo en ribagorzano, en donde se palataliza la $\mathrm{L}$ y se conserva la consonante inicial.

${ }^{16}$ Sin que puedean se consideradas cultismos o dialectalismos. Vid. A. Badía: «Por una revisión del concepto de <cultismo > en fonética histórica», Studia Hispánica in Honorem R. Lapesa, I, Madrid, 1972, pp. 148-150.

17 Vid. R. Menéndez Pidal: Orígenes del español, Madrid, 1964, pp. 238-239. Vid. también R. Lapesa, ob. cit, y R. Pellen RLiR, 40, 1976, pp. 241-257. 
Por si lo dicho no bastase, recordemos el verso 2052 de nuestro texto en donde son citados los famosos infantes de Carrión; pues bien, «infante» con el valor de «hijo de padre noble» no se da en el siglo XIII, época en la que ya la palabra se reserva para los hijos del rey ${ }^{18}$.

\subsection{Yendo ya al comentario del fragmento estudiaremos:}

$\left.1^{9}\right)$ la estructura externa del relato (rima, recursos formulísticos, etc)

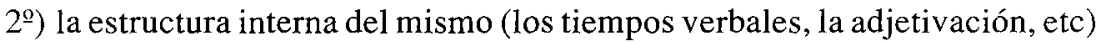

$\left.3^{\circ}\right)$ algunos elementos lingüísticos que merezcan ser comentados

19) Ya sabemos que la métrica del Poema es irregular, y que consta de una serie de versos monorrimos con rima asonante -en nuestro tex to O-E-. Según Pellen ${ }^{19}$, esta rima surge a partir del verso 1885 , ello incide sobre las posibles separaciones o particiones del cantar, problema complejo en el que no vamos a entrar $^{20}$. Todos sabemos que la literatura medieval estaba destinada, por regla general, a ser recitada, a ser leída en voz alta, y que en poemas largos, como el que nos ocupa, las fórmulas repetitivas tenían - y tienen - un importante valor nemotécnico, por ello las rimas no son «difíciles»; lo que predomina —si examinamos la serie O-E en la que está inserto nuestro texto (un total de 143 versos)- es el uso de los nombres propios (35 versos), seguido por los indefinidos (24 versos); incluso podríamos puntualizar más: de los nombres propios Campeador aparece 11 veces, Carrión 6, Alfonso 4, etc.; otras palabras con un relativo índice de frecuencia son: son (8), vos y señor (6), noch y pro (5), corazón y yo (4), etc. Es decir, los nombres propios suponen el $24 \%$ de la rima, y, si los unimos a los indefinidos, el índice sube al $48 \%$.

Esto es así, en parte, por el constante uso de fórmulas fijadas, Según Waltman $^{21}$, del 20 al $25 \%$ del Poema son fórmulas; Por otro lado Aguirre ${ }^{22}$ ha señalado que el nombre propio tiene la tendencia a situarse en la rima —en

18 Lapesa, ob. cit.

19 «Cantares de Mio Cid: Vocabulaires exclusifs», Cahier de linguistique hispanique médiévale, 8 , 1983. pp. 5-155.

20 Además de la conocida división en tres cantares, conocemos la propuesta por M. García Gómez: Mio Cid. Estudios de endocrítica, Barcelona, 1975. Especialmente pp. 155-171. Vid. también J. Horrent: Historia y poesía en torno al cantar del Cid, Barcelona, 1973; y F. López Estrada, ob. cit., pp. 51 y ss.

${ }^{21}$ «Fórmula and theme in the Cantar de Mio Cid", H, 63, 1980, pp. 20-23. La insistencia en las estructuras formulísitcas es constante en la crítica; citaremos, entre otros, los siguientes trabajos: M? Chaplin: «Oral-Formulaic Style in the Epic: a progress report», Medieval Hispanic Studies... to Rita Hamilton, Londres, 1976, pp. 11-20; E. Chasca: El arte juglaresco en el Cantar de Mio Cid, Madrid, 1967; A.D. Deyermond: «Estructural and Stylistic Pattern in the PMC», Medieval Studies in honour of R. W. Linker, Madrid, 1973,pp. 55-71; y «Tendences in Mio Cid Scholarship, 1943-1973», en A.D. Deyermond: Mio Cid Studies, Londres, 1977, pp. 13-47; J.J. Duggan: «Formulaic Diction in the CMC and the Old French Epic», Form for Modern Language Studies, 10, 1974, pp. 260-269.

22 «El nombre propio como fórmula oral en el Cantar de Mio Cid», La Crónica, 92, 1981, pp. 107-119. El estudio más completo sobre el nombre propio en el Poema es el de R. Pellen: «Le Poema du Cid. Vocabulaire des Noms Propres», Cahiers de linguistique hispanique médiévale, 1, 1976, pp. 7-99. 
nuestro texto-Alfonsso (versos 2013, 2024, 2026 y 2030), Campeador (versos $2014,2027,2030$ y 2049), Carrión (verso 2052) y Criador (versos 2043 y 2055).

Dentro de las fórmulas encontramos el que en buen ora naçió (versos 2008 , 2016 y 2020), alma e coraçón (versos 2004 y 2033) y de día e de noch (versos 2002 y 2045). Fijémonos que dos de ellas constan de una pareja de apelativos. El empleo de parejas es constante ${ }^{23}$. la primera podría ser considerada como una pareja poética puesto que el segundo adjetivo no parece añadir nada a la significación, es más bien intensificador o, si se quiere, retórico - uno de los recursos de la amplificatio-. Por el contrario la segunda pareja - día e nochconstituye una de las llamadas "parejas inclusivas», es decir aquellas que sirven para indicar la totalidad -noche y día = siempre $-{ }^{24}$; son muy frecuentes en todas las épocas y mantiene su vigencia en el habla actual —pitos y flautas, dimes y dieres, etc-.

Nuestro texto presenta dos partes claramente diferenciadas: la primera, que iría hasta el verso 2025, es exclusivamente narrativa, en la segunda predomina el estilo directo. En la primera podríamos hacer pequeñas separaciones:

a) (versos 2002-2008) El Çid deja todo dispuesto en Valencia para que no suceda nada en su ausencia.

b) (versos 2009-2019) EI Çid va a entrevistarse con el rey

c) (versos 2013-2019) Preludio del encuentro

d) (versos 2020-2025) Homenaje del Çid al rey

Esta estructuración tiene diferentes finalidades: la primera sirve para mostrar la prudencia del Çid — clara en el verso 2026: tan buen varón = prudente-, la segunda para mostrar la riqueza del Çid, en la tercera señalaremos que se indica que el rey ha llegado el día anterior -importante, como veremos-, y la cuarta hace hincapié en el vasallaje del Cid hacia el rey, tan importante en el Poema y expresada en el verso 2024: «Así sabe dar omildança a Alfonso so señor».

Como decíamos, la segunda parte - desde el v 2026 - está dominada por el diálogo; sólo hay un pequeño fragmento narrativo (versos 2039-2042):

«Hioios fitos las manos le besó

Levos en pie \& en la bocal saludó

Todos los demás desto auien sabor

Pesó a Albardiaz \& a Garciordoñez»

Estos cuatro versos separan la primera parte del diálogo -con el perdón del Cid- de la segunda - los agasajos de la reconciliación-. No se puede decir más en menos palabras: Una vez concedido públicamente el perdón real, el Cid le besa las manos, se levanta y le besa en la boca. El poeta nos está diciendo lo

\footnotetext{
${ }^{23}$ La bibliografia no es escasa: E. Caldera: «L'oratoria nel Poema de Mio Cid», Miscellanea di studi ispanici, 1965, pp. 5-29; C. Smith: Estudios cidianos, Madrid, 1977, pp. 164-217.

${ }^{24}$ Recuerdo una oración que rezaba de pequeño que decía: Angel de la guarda / dulce compañía / no me desampares /ni de noche ni de día.
} 
siguiente: El Cid se reconoce vasallo del rey —el beso en la mano ${ }^{25}$ - pero no es un vasallo cualquiera, sino un amigo, uno de sus íntimos, y por eso, de pie, le besa en la boca ${ }^{26}$. Además en dos escuetos versos se nos expresa la alegría de sus amigos y el pesar de sus enemigos ${ }^{27}$.

Vamos a estudiar el diálogo. El estilo directo comienza en el verso 2027:

«Tan grand pesar ouo el rey don Alfonsso:

Levantavos en pie, ya Çid Campeador»

Fijémonos que no hay ningún verbo dicendi introductorio del estilo directo. Este hecho es muy frecuente en el Poema - como puso de manifiesto D. Alonso ${ }^{28}$ (veamos también los versos 2030-2031 y 2052-2053) y se da también en los romances, mientras escasea en el mester de clerecía. El estilo directo sin verbo introductorio se da en un $41^{\prime} 6 \%$, mientras que en La Chanson de Roland este hecho sólo representa el $2^{\prime} 6 \%$. E. Caldera ${ }^{29}$ ha señalado que generalmente los verbos decir y hablar sirven para introducir parlamentos cortos, sonreir para discursos de tono familiar o suave, y los demás verbos dicendi para los discursos solemnes o muy significativos. A este respecto destaquemos el verso 2055:

«Respuso mio Çid: «assí lo mande el Criador»»

Es decir: «Dios lo quiera». Este corto parlamento es muy importante -de ahí la utilización de responder ${ }^{30}$-; recordemos que en el verso anterior los infantes de Carrión, en su primera aparición, le han dicho al Cid:

«En quanto podemos andamos en vuestro pro»

La frase del Cid es «ya lo veremos» con la que el poeta adelanta la acción del robledal de Corpes.

La «voluntad de estilo» es a veces tan fuerte como para distinguir los verbos dicendi por personajes; así vemos en los vv 2033 y 2047 cómo se especifica la frase dixo el rey, mientras que en los versos 2036 y 2043 el Cid fabló e dixo; bien es cierto que son variaciones estilísticas, pero sin duda significativas, aunque tengan también un cierto componente formulístico.

El estilo directo es tan importante que representa nada menos que el $44^{\prime} 35 \%$ del total -unos 1670 versos-. Se ha dicho que este uso sirve para expresar la vivacidad en la narración.

En el segundo diálogo — verso 2043 y ss.- el Cid quiere que el rey sea su huésped, a lo que éste se opone curiosamente no por el argumento de su autoridad

\footnotetext{
25 Vid. Menéndez Pidal Cantar de Mio Cid. II, sv. besar; C. Smith, ob. cit., pp. 236-239.

${ }^{26}$ Todavía hoy se saluda con un beso en la boca en algunas culturas como la rusa.

${ }^{27}$ Es interesante que el verso 2041 anticipa el verso siguiente: «todos los demás» (salvo Alvar Díaz y Garci Ordòñez).

28 «El anuncio del estilo directo en el Poema del Cid y en la típica francesa», Obras Completas, II, Madrid, 1972, pp. 195-214. Por todo este tema se hace necesario consultar el importante libro de J. L. Girón: Las formas del discurso referido en el Cantar de Mio Cid, Madrid, 1989. Cita nuestros versos en las pp. 238-239.

${ }^{29}$ Art. cit. nota 30.

${ }^{30}$ Seguramente con un sentido de réplica, como hoy respondón o contestatario - salvando todas las distancias.
} 
sino por haber llegado antes: recuérdese que este hecho había sido señalado con anterioridad - verso 2013-.

Por último queremos poner de relieve un aspecto que en numerosas ocasiones se ha resaltado ${ }^{31}$ : la alegría del Cid, que en nuestro texto hace incluso que llore de contento ${ }^{32}$ - verso 2023 -.

2o ) La estructura interna

Como es sabido, el tiempo de la narración en el pasado es el indefinido, mientras que el tiempo de la descripción es el imperfecto ${ }^{33}$. Por otra parte no hemos de olvidar que el valor de "presente de un pasado» que tiene el imperfecto, lo que le habilita para expresar acciones que ocurren en un pasado o comentarios en dicho tiempo. Pondremos algunos ejemplos:

Quando vieron que viene el buen Campeador

A todos los sos estar los mandó

si non a estos cavalleros que querie de coraçón

(vv. 2017-2018)

Las yerbas del campo a dientes las tomó

lorando de los oios, tanto auie el gozo mayor

(vv. 2022-2023)

En el primer ejemplo el imperfecto vinie se explica porque esta acción es coetánea, simultánea, de la del indefinido. El querer del segundo ejemplo nos indica tanto la simultaneidad como la atemporalidad en el pasado narrativo; pensemos qué ocurriría si el verbo querer lo pusiéramos en indefinido. En el tercero el imperfecto está usado porque se trata de un comentario de la acción principal, además de por lo dicho anteriormente.

Los tiempos que predominan son el indefinido y el presente, seguidos a larga distancia del imperfecto. El dato no es significativo: si es una narración en el pasado y si hay estilo directo, es normal el dominio de ambas formas temporales; pero el presente se da también en la parte narrativa.

Conviene que repasemos ahora los apartados que establecimos de este fragmento narrativo. El primero iba del verso 2002 al 2008, en él predomina el presente - es, tiene, sirven, puede y torne-; en el segundo (2009-2012) es el imperfecto - salien, gañara y dieran ${ }^{34}$ - En el tercero y cuarto es el indefinido el que abunda. Vemos, por lo tanto, cómo a cada unidad temática le corresponde un uso diferenciado de tiempos. Vamos a detenernos en el estudio pormenorizado de un fragmento:

${ }^{31}$ L.H. Allen: «A Structural Analysis of the Epic Style of the Cid», Structural Studies on Spanish Themes, Salamanca, 1959, pp. 345-414.

${ }^{32}$ Para la expresión llorar de los ojos vid. más adelante.

${ }_{33} \mathrm{Vid}$. H. Weinrich: Estructura y función de los tiempos en el lenguaje, Madrid, 1969. El análisis de las formas temporales lo ha realizado también Rafael Cano en su citado comentario.

${ }^{34}$ Las formas en -ra tienen el valor etimológico de pluscuamperfecto de indicativo. 
Hyas va pora las vistas que con el rey paró

De un día es legado antes el rey don Alfonsso

Quando vieron que vinie el buen Campeador

Recebir lo salen con tan grand onor

Don lo ouo a oio el que en buen ora naçió

A todos los sos estar los mandó

(vv. 2012-2017)

Aparentemente es un uso caótico de los tiempos: presente - pretérito perfecto ${ }^{35}$ - indefinido - imperfecto - presente - indefinido - indefinido. Este empleo alternante se da también en los romances, y no es arbitrario sino que intervienen en él diversos factores ${ }^{36}$. Veámoslo: El primer verbo, en presente, va precedido del adverbio $y a$; las expresiones adverbiales temporales favorecen el uso del presente, como comprobamos en el verso 2052 , que va precedido por dos indefinidos:

Essora se le omillan los yffantes de Carrión

pero ello no explica el presente del verso 2015 salen, ni el que podemos ver en el 2024:

\section{Así sabe dar omildança a Alfonsso so señor}

El presente en estos casos tiene un valor estilístico: sirve para dar variedad a la narración en el pasado, y, ni que decir tiene, para acercar «psicológicamente» la acción al oyente, de ahí su empleo en el último verso citado que es una especie de comentario del juglar.

No deja de sorprender el uso del pretérito perfecto es le gado ${ }^{37}$ por cuanto que las formas compuestas son muy escasas, sólo suponen el $5^{\prime} 94 \%^{38}$, empleándose el indefinido para el valor de pasado inmediato, como podemos ver en el verso 2048:

Vos agora legastes \& nos viniemos anoch ${ }^{39}$

35 Empleo la terminología tradicional, aun cuando personalmente prefiero la de A. Bello.

36 Vid. además de los datos ofrecidos por Menéndez Pidal en su gramática del Cid, J.M. Aguirre: «Rima y oralidad», La Crónica, 7, 2, 1979, pp. 107-108; J.C. Chevalier: «Architecture temporelle du Romancero tradiconal», BH, LXXIII, 1971, p. 50-103; S. Gilman: Tiempo y formas temporales en el Poema de Mio Cid, Madrid, 1961; R. Lapesa: «la lengua de la poesía épica en los cantares de gesta y en el romancero viejo». De la edad media a nuestros dias, Madrid, 1967, pp. 9-28; M. Magnotta: Historia y bibliografia de la crítica sobre el Poema de Mio Cid, Chapel Hill, 1976; I. Michael, «Tres duelos...», cit. nota15; T. Montgomeri: «Narrative tense preference in the Cantar de Mio Cid», RoPh, XXIm 196768, pp. 253-274; U. Scheweizer: Die erzälenden Vergangenheitstemporaim Altspanischen ( $P M C »), Z$ Zurich, 1974; J. Szertics: Tiempo y verbo en el romancero viejo, Madrid, 1967.

37 Como es sabido en la Edad Media coexistían haber y ser como morfemas de la expresión de las formas verbales compuestas. Ser era el «auxiliar» de los verbos intransitivos y reflexivos, haber el de los transitivos; es decir: como hoy en francés e italiano; sin embargo ya en el cid puede encontrarse haber con intransitivos. En el siglo XVI ya hay autores que sólo emplean haber. Vid: R. Pellen: «Les temps composés et le traitement du participe avec «haber» dans le Poeme de Mio Cid, Cahiers de linguistique hispanique médiévale, 9, 1984, pp. 49-97; N. Vicent: «The Development of the Auxiliares habere and Esse in Romance», en Studies in the Romance Verb, Kent.

${ }_{38}$ Vid. R. Pellen: «Poerna de Mio Cid. Le systême verbal», Cahiers de linguistique hispanique médićvale, 4, 1979, pp. 71-135.

39 De todas formas es hecho conocido que en amplias zonas de habla hispana se ha perdido la diferenciación entre el indefinido y el pretérito perfecto. Recuérdese - por ejemplo- la ausencia del empleo del pretérito perfecto en Asturias, Méjico, etc. 
La explicación del pretérito perfecto que citábamos es también de tipo estilístico: es el enlace narrativo-temporal entre el presente del verso anterior y el indefinido del verso siguiente ${ }^{40}$.

Quizá uno de los elementos linguí́sticos que más hayan llamado la atención al lector no especialista haya sido el uso de los verbos auxiliares copulativos ser, estar haber y tener. Para una mayor comodidad vamos a citar los versos en que se encuentran los mencionados verbos auxiliares:

2003 Dentro es su mugier

2004 En que tiene su alma

2016 Don lo ouo a oio

2017 A todos los sos estar los mandó

2023 Tanto auie el gozo mayor

2026 Tan grand pesar ouo

2030 Hioios fitos sedie el Campeador

2032 Assí estando dedes me vuestra amor, que lo oyan quantos aquí son

2038 Estas mesnadas que están a derredor

2041 Todos los demás desto auien sabor

2044 Quanto he la graçia de don Alfonsso

Ciertamente he omitido los verbos haber y ser cuando son exponentes o morfemas de las formas compuestas de los verbos: ha recabdado (v. 2006) o es legado (v. 2013).

Examinemos la pareja serlestar. Ser en la Edad Media tenía el conocido valor de la atemporalidad en la atribución, es decir, no estaba tan acusado el carácter locativo que hoy tiene, de ahí que en el verso 2003 se emplee ser, cuando en nuestros días utilizaríamos estar. En este sentido - y para no alargar demasiado esta exposición ${ }^{41}$ —es sintomático el verso 2032: estando significa «permaneciendo» (pero en un estado transitorio), son tiene un valor existencial (=»hay») ${ }^{42}$. Interesante es el sedie del verso 2030 , que tiene el valor de «permanecer».

Si estudiamos las frases con haber/tener podremos apreciar que el verbo haber se emplea con términos abstractos: gozo 2023, pesar 2026, sabor 2041, gracia 2044. Tener se usaba más con los concretos, por otra parte haber/ tener tenían los valores que hoy se encuentran, por ejemplo, en italiano, es decir: tener signifi-

${ }^{40}$ Otro ejemplo de simple con valor de compuesto lo tenemos en la comidia del verso 2020.

${ }^{41}$ La bibliografía es extensa; citaré los siguientes trabajos: J. Bouzet: «Orígenes del empleo de estar», Estudios dedicados a Menéndez Pidal, IV, Madrid, 1953, pp. 37-59; J.D.M. Ford: «Sedere, Essere and Stare in the Poema del Cid», MLN, XIV, 1899; J.A. Ribeiro: «Essere, sedere e stare nas linguas romanicas», Boletim de Filología, 17, 1959, pp. 147-76; J. Roca Pons: Estudios sobre perifrasis verbales del español, Madrid, 1958; H. Zamora Elizondo: «Una pesquisa acerca del verbo <haber>», BICC, IV, 1948, pp. 580585; J. M. Saussol: Ser y estar. Origenes de sus funciones en el Cantar de Mio Cid, Sevilla, 1977.

${ }^{42}$ Recordemos los versos de Fray Luis de León: «Que descansada la vida / la del qye huye del mundanal ruido / y sigue la escondida / senda por donde han ido / los pocos sabios que en el mundo han sido». 
caba la posesión durativa (=retener, mantener, etc), de ahí su uso en el verso $2004^{43}$.

El léxico del fragmento gira en torno a las dos partes que establecimos, así palabras como fablar y decir lógicamente aparecerán sólo en la segunda parte, en el diálogo. La voz que más veces encontramos es bueno, seguida de rey, a continuación tendríamos las siguientes: fablar, dezir, señor y pies, besar, mano y amor. Una serie de ellas deben su alta frecuencia a que son fórmulas, como sucede con bueno, ora y nacer, por la repetición del sintagma el que en buen ora naçió, y otro tanto cabe decir de día, fincar e ioios. No es de extrañar la repetición de bueno, decir y rey porque son tres de las palabras con mayor índice de aparición -en más de 200 ocasiones $^{44}$ _. Dejando fuera bueno, nacer, ora y día ${ }^{45}$, tendríamos aparentemente dos campos semánticos: el campo del «sentimiento» _-amor, corazón ,besar - y el campo del «cuerpo humano»-corazón, mano, inoio, pie-. Estos campos se acrecientan con otras palabras del texto: alma, llorar, gozo, pesar, etc. Ahora bien, el segundo campo es falso porque sus términos pertenecen también al primero en un sentido amplio: por ello conviene considerar que todos ellos se integran en un campo que podríamos llamar de «vasallaje».

Si fablar y decir se daban en la segunda parte de nuestro texto, en la primera los verbos que abundan son los de movimiento: ir, venir, tornar, llegar y salir. Precisamente este último ha sido estudiado por Hills ${ }^{46}$, que nota que salir predomina en la segunda mitad - a partir del verso 1879 -, mientras que el verbo exir, el más frecuente en la primera mitad, no aparece en la segunda. Ello tiene que ver con el tema de los dos autores del Poema, que no vamos a tratar ${ }^{47}$. La frecuencia de verbos de movimiento está motivada por la acción preparatoria de la reunión con el rey, claro es.

La adjetivación es escasísima y pobre. Además de las siete veces que aparece bueno, casi siempre en la fórmula ya vista - menos en el verso 2006 buen varón y en el 2014 buen Campeador-, sólo tenemos grand - versos 2015 y 2026-, mayor - verso 2023 - y gruessos y corredores - verso 2010_. Así pues, encontramos un adjetivo formulístico valorativo de tipo «maniqueista» bueno- otros dos valorativos ponderativos - grand y mayor - y dos descrip-

43 Vid. E. Seifert: «Haber y tener como expresiones de la posesión en español», RFE, XVII, 1930, pp. $233-276$ y $345-389$.

${ }^{44}$ Vid. los magníficos estudios de R. Pellen en los Cahiers de linguistique hispanique médiévale.

${ }_{45}$ Por cuanto su aparición es formularia como acabamos de decir.

46 «The Unity of the Poema del Cid», H, XII, pp. 113-118.

${ }^{47}$ Desde la conocida tesis de don Ramón — «Dos poetas en el Cantar de Mio Cid», Barcelona, 1970— hasta las investigaciones de H. Corbató: «La sinonimia y la unidad del Poema del Cid», $H R, 9,1941$; G. Orduna: «Las técnicas de la estructura y la intervención de dos juglares en el Poema de Mio Cic», Studia Jispanica in Honorem R. Lapesa, II, Madrid, 1974. pp. 411-431; O.T. Myers: «Multiple Authorship of the Poema de Mio Cid: a final word?» en Mio Cis Studies, Londres, 1977, pp. 113-128; F.M. Waltman: Unity of Authorsip of the Poema de Mio Cid, U. de Pennsylvania, 1971; «Formulaic Expression and Unity of Authorship in the Poema de Mio Cid», H, 56, 1973, pp. 569-578; «Authoship in the Cantar de Mio Cid», Revista de estudios Hispánicos, IX, 1975, pp. 45I-469. 
tivos - gruessos y corredores-. Bien poco es. Ahora bien, esta pobreza no es rasgo estilístico del Poema como tal, pues se da en todas las obras en las que predomina la acción sobre la descripción; el maniqueísmo en la adjetivación es general en toda la Edad Media - y sobre todo en la literatura de corte didáctico-.

Buen es uno de los 32 epítetos que se aplican al $\mathrm{Cid}^{48}$. «Buenos» son considerados nuestros héroes, Minaya y Alvar Fáñez. Don Alfonsso, por el contrario, no suele ser calificado sino determinado por los apelativos rey y señor, aunque a veces se le llama honrado.

Mayor no tiene valor comparativo, sino superlativo absoluto o ponderativo ${ }^{49}$ $(=»$ tan grande»).

Gruessos y corredores es otra pareja formulística que se repite en el Poemaversos 1336 y $1968-^{50}$. La adjetivación de caballos, mulas y palafranes es constante $^{51}$. Es importante destacar que las parejas de adjetivos se emplean en la épica para los paisajes, las espadas, las personas y, como aquí, los caballos; por el contrario, en el mester de clerecía se usarán más para expresar notas emotivas. Que un caballo sea ponderado como corredor es normal, pero no deja de extrañar que un caballo corredor sea gordo - grueso-; claro es que la gordura suele ser considerada como positiva y la delgadez como negativa - y no sólo en los caballos-, de ahí que el andalucismo jamelgo venga de famélico. Sin embargo creo que aquí el significado de gruesso no tiene que ver con la abundancia de carne sino con el tamaño, es decir, creo que en el Poema tiene este adjetivo el significado que posee en catalán y en galorrománico: «grande» ${ }^{52}$.

La sintaxis no es muy complicada. La oración o la subordinación no ocupa más de un verso, no hay abuso de la coordinación, como sucederá en la prosa didáctica de los siglos XIII y XIV. Las suboraciones más frecuentes son las introducidas por $q u e$, bien en función adjetiva — versos 2004, 2005, 2012, 2017 y 2038-, bien en función sustantiva - versos 2002, 2007, 2014 y 2050-, además de las que aparecen en la repetida fórmula el que en buen ora naçióo ${ }^{53}$, siguen en frecuencia las temporales y condicionales. Los demás tipos de subordinación son más infrecuentes ${ }^{54}$. Quizá merezca la pena hablar someramente de la estructura que vemos en el verso 2055: «assi lo mande el Criador». No cabe ninguna duda de que se trata de una

${ }^{48}$ Vid. entre otros, los siguientes estudios: E. Chasca: ob. cit.; F. López Estrada: ob. cit.; R. Hamilton: «Epic epithets in the Poema of the Cid», Revue de Litterature Comparée, 34, 1961; R.H. Webber: «Un aspecto estilístico del CMC», Anuario de Estudios Medievales, 2, 1965, pp. 485-496.

${ }^{49}$ Vid. R. Lapesa, art. cit. Este adjetivo ha tenido importancia en el tema de la datación del Poema.

${ }^{50}$ Vid. Menéndez Pidal, Cantar de Mio Cid, cit., II, sv. cauallo.

"Y Y también formulística. La estructura «tanta gruessa mula e tanto palafré de sazón» se repite en los versos 1987,2114 y 3243, más la variante del verso 2572.

52 Y también en alemán großj.

${ }^{53}$ Es claro que evito denominarlas oraciones sustantivas y adjetivas.

54 Vid. A. Badía: «Dos tipos de lengua cara a cara», Homenaje a Dámaso Alonso, I, Madrid, 1960, pp. 115-139. Hay que desechar la hipótesis de un influjo vasco en la sintaxis, como pretende T. Montgomery: «Basque Models form some Syntactic Traits of the Poema de Mio Cid», BHS, 54, 2, 1977, pp. 95-99. 
oración desiderativa ${ }^{55}$, y lo digo por la problemática interpretación del famoso verso 20 -Dios que buen vasallo si oviesse buen señor-, sobre el que se ha dicho que podría ser una oración desiderativa, pero nunca ni en el Cid ni en la Edad Media puede aparecer un imperfecto de subjuntivo con una oración desiderativa, por lo que la única interpretación posible es la de condicional.

Los elementos retóricos no faltan. Según Darbord ${ }^{56}$, el lenguaje de la epopeya se caracteriza por las figuras de contiguiidad, como la metonimia, mientras que la metáfora estaría ausente, salvo las lexicalizadas ${ }^{57}$. Es ya un tópico referirse a la expresión llorar de los oios como ejemplo de pleonasmo en el Poema ${ }^{58}$, como no hace mucho ha demostrado J. A. Pascual ${ }^{59}$, no se trata de una figura retórica, puesto que en la Edad Media existía una oposición significativa entre llorar y llorar de los oios; recordemos que plorare en latín significaba «gritar, gritar llorando, lamentarse, llorar gimiendo»; era, pues, una manifestación en voz alta del dolor, por ello, cuando el llorar era silencioso, se hacía necesario especificarlo con «de los oios», es decir, «derramando lágrimas».

$\left.3^{\mathbf{g}}\right)$ Comentario de algunas palabras y expresiones

Amas (=ambas) (v. 2003): El grupo MB latino suele reducirse en español a M, como sabido, pero no siempre — cambiar, ambos, tambor, etc-. Se ha hablado de dialectaslismo en estos casos, pero seguramente no es cierto. Durante un largo periodo de tiempo la lengua vaciló entre soluciones «conservadoras» con MB y soluciones «innovadoras» con M. La forma amas llega al siglo XVI.

Fata (v. 2008): Como todos sabemos, la preposición hasta es un arabismo del español. La forma que tenemos dura hasta fines del siglo XIII; en este siglo alternan fata y fasta, y en el XIV se generaliza la segunda forma.

Pora (v. 2012): Es la forma preposicional que predomina hasta el último cuarto del siglo XIII. Para aparece a mediados del siglo XIII y no se generaliza

${ }^{55}$ La bibliografía es extensa. Remito al libro de López Estrada.

56 «Etude du language de l'épopée castillane: vers une définition de la métonymie», Cahier de linguistique hispanique médievale, 4, 1979, pp. 137-172.

${ }^{57}$ Como la que encontramos en el verso 375: «assís parten unos d'otros commo la uña de la carne». Para las posibles figuras retóricas, vid. M. Garci-Gómez, ob. cit.

${ }^{58}$ Dejando fuera el problema de si esta expresión procede o no de la épica francesa. Para este influjo vid. K. Adams: «Pensar de: Another Old French Influence on the Poema de Mio Cid and other Medieval Spanish Poems», La Coronica, 7, 1, 1978, pp. 8-12; D. Alonso: «El anuncio del estilo directo en el Poema del Cid y en la épica francesa», Melanges... Rita Lejeune, Gembloux, 1969, pp. 379-393; R. de Dardel: «A propos de la construction respunt Rolland + discours direct», TRLL (Mel.J. Rychner), 1978, pp. 107. 116; J.J. Duggan: «Formulaic Diction in the Cantar de Mio Cid and the Old Frech Epic», Forum for Modern Language Studies, 10, 1974, pp. 260-269; M. Herslund: «Le Cantar de Mio Cid et la chanson de geste», Revue Romane, 9, 1974, pp. 69-121; J. Horrent: «El Cantar de Mio Cid frente a la tradición rolantina», en Historia y poesia, cit.; F. López Estrada: ob. cit., pp. 198 y ss.; R. Menéndez Pidal: «La épica medieval en España y Francia» y «Fórmulas épicas en el Poema del Cid», ambos en En torno al Poema del Cid, cit.; C. Smith: «Further French Analogues and Sources for the Poema de Mio cid», La Coronica, 6, 1977, pp. 14-21; y Estudios cidianos, cit.

59 «Del silenciosollorar de los ojos», El Crotalón, 1, 1984,pp. 799-804. Hablan también de la expresión Horrent, ob. cit., pp. 360-361; M. Garci-Gómez: ob. cit., p. 257; C. Smith: Estudios, cit., pp. 247-249. 
hasta fines del siglo citado. En consecuencia, el para que se da una vez en el Poema hay que atribuirlo al copista.

Parar (v. 2012): Tiene el significado etimológico de «preparar», verbo éste que no entra hasta el siglo XVII.

Inoio (rodilla) (vv. 2021 et alia): Procede del latín genuculu, se da en toda la Edad Media. Entra en declive en la segunda mitad del siglo XVI, y en el siglo XVII sólo aparece como arcaísmo.

Feches (v. 2029), feré (v. 2033): El verbo facere tenía el acento sobre la A; al perderse la tercera conjugación latina, los verbos con $\mathrm{E}$ pasaron a los en ER o en IR, sin embargo quedaron restos de esta primitiva conjugación. Me explico: hacer tiene el acento en la E, luego ha cambiado el acento latino, como acabamos de decir; ahora bien, pudo conservarse fácere, con lo que la E era átona, y por lo tanto se perdió - * facre-, la C se vocalizó en $\mathrm{Y}$ - fayre- - y cuando iba seguida de $\mathrm{T}$ palatalizó a esta consonante en /c/. Luego la Y pudo perderse o palatalizar a la A:

$$
\begin{aligned}
\text { facere } & >\text { fac-ere }>\text { fayre }>\text { feyre }>\text { fere } \\
& >\text { fare }(\text { de donde el español har }- \text { é }) \\
\text { facetis } & >\text { factis }>\text { factes }>\text { faytes }>\text { feytes }>\text { feces }
\end{aligned}
$$

Vuestra amor (v, 2032): En el Poema se da como masculino o como femenino. Puede ser uno de los orientalismos del Poema, pues la palabra es femenina en Berceo y en aragonés.

Levar (v. 2040): Durante la Edad Media alternaban levar y levantar --vid. v. 2027- Levar cae en desuso en la segunda mitad del siglo XVI, salvo como término náutico.

Cras (=mañana) (v. 2050). Se pierde seguramente a fines del siglo XIV ${ }^{60}$.

Finalmente señalaré el verso 2019 muy interesante tanto por el empleo del indefinido plural, raro en la Edad Media, como por la coexistencia del indefinido con el numeral, en un número tan bajo - que todavía hoy se usa cuando se desconoce el número exacto (seremos unos seis) - y que choca con la puntualización detallista numérica que en ocasiones aparece en el Poema, como -por ejemplo- en el verso 1717: «quatro mill menos treinta con mio Cid van a cabo».

\section{CONCLUSIÓN}

Hemos intentado examinar algunos problemas y cuestiones de un texto medieval. No hemos pretendido realizar un comentario exhaustivo, por lo que sólo nos hemos detenido en aquellos puntos que nos parecían más interesantes o más desconocidos.

${ }^{60}$ Vid. M. Ariza: «Diferencias textuales en los manuscritos del Libro de los Buenos Proverbios», AEFUEx, V, 1982, pp. 7-16. 